\title{
Conceptual development and change precede adults' judgments about powerful appearance
}

\author{
Brandon F. Terrizzi \\ Cincinnati Children's Hospital Medical Center, Division of General and Community \\ Pediatrics \\ Brandon.Terrizzi@,cchmc.org
}

This paper is in press at Adaptive Human Behavior and Physiology and may differ from the final published version after proof- and copy-editing.

Conflicts of Interest: The author has no conflicts of interests to disclose regarding the contents of this manuscript.

Acknowledgements: I am grateful to Evan Westra and Libbie Brey for comments on an early version of this manuscript, and to Barnaby Dixson and two anonymous reviewers for comments on a later version. The writing of this manuscript was partially supported by training funds from the Bureau of Health Professions (BHPr), Health Resources and Services Administration (HRSA), and Department of Health and Human Services (DHHS) under grant number T32HP10027. 


\begin{abstract}
Objective: Adults' mental representations of the physical appearance of people that are "strong" and people that are "in charge" are remarkably similar. Some have explained this feature of adults' thinking by positing innate mental representations. However, specific details about the nature and structure of these representations and an appropriate empirical foundation for these claims has been lacking. In this review, my objective is to provide a high-level summary of recent research exploring infants' and young children's intuitions about the physical manifestations of power. I argue that the social responses and judgments of young participants are more informative about the existence and nature of putatively innate mental content.
\end{abstract}

Methods: Narrative review of developmental studies.

Results: Preverbal infants exhibit a remarkably early sensitivity to the relative power of two agents. By the time that people enter childhood, they exhibit increasingly adult-like intuitions about powerful appearance. Additionally, there are significant revisions in the appearance-to-power correspondences that people detect between childhood and adulthood.

Conclusions: These complex developmental patterns are inconsistent with the idea that adults' intuitions about the physical manifestations of power are straightforward outputs of an innate psychology. Rather, despite an early-emerging sensitivity to appearancebased cues to power, significant conceptual development and change precede adults' judgments about powerful appearance.

Keywords: dominance, strength, facial appearance, nonverbal behavior, social evaluation, infants, children 
In order to thrive, people must make adaptive predictions about their environment. This is especially true of the social environment where misjudging another person's intentions or social standing can have severe consequences. One strategy for diagnosing these characteristics is to be cautious; deliberately withholding judgment about a person until observing their behavior and interaction style across multiple contexts. However, in some situations this strategy is not practical. If it is our first day on the job or stepping out onto the prison yard, we will be highly motivated to quickly apprehend the social standing of others and to adjust our behaviors appropriately. However, unless we see a single individual or group exhibit control, or someone takes the time to explain existing power dynamics to us, the most adaptive strategy may be to act based on our first impressions. Particularly when interacting with unfamiliar people, our first impressions about who holds power will likely be based on information that is publicly visible, such as others' non-verbal behaviors and their physical appearance.

As adults, we often use information about people carry themselves to decide if they are powerful. For example, people enacting broad and expansive poses are more likely to be viewed as powerful, proud, and in charge relative to people enacting diminutive poses (Burgoon, Buller, Hale, \& Turck, 1984; Durkee, Lukaszewski, \& Buss, 2019; Shariff \& Tracy, 2009; Tracy \& Robins, 2008). We also use more subtle cues like an upward head tilt, smiling, and a person's willingness to engage in eye-contact to estimate their subjective feelings of power and status (Brey \& Shutts, 2015; Foulsham, Cheng, Tracy, Henrich, \& Kingstone, 2010; Hecht \& LaFrance, 1998; Tracy, Cheng, Robins, \& Trzesniewski, 2009; Witkower \& Tracy, 2019). Of course, these behaviors are dynamic, and people often change how they carry themselves across social contexts. 
Thus, someone might adopt a confident and expansive posture in some forms of company but not others. Because of this, we gain the most insight about the nature and extent of a person's control by tracking their behaviors across multiple contexts, but this does not stop people from responding to these behaviors upon first encountering them (Hall, Horgan, \& Murphy, 2019; Holland, Wolf, Looser, \& Cuddy, 2017).

We also associate power with aspects of appearance about which others have limited control. For example, we use inherent aspects of others' facial appearance to decide if they are powerful. A person with stern and prototypically masculine facial features is more likely to be viewed as aggressive, driven, and having greater authority relative to someone possessing more neutral or prototypically feminine features (Holzleitner \& Perrett, 2016; Keating, Mazur, \& Segall, 1977; Oosterhof \& Todorov, 2008; Rule, Adams, Ambady, \& Freeman, 2012; Todorov, Said, Engell, \& Oosterhof, 2008; Toscano, Schubert, \& Sell, 2014; Toscano, Schubert, Dotsch, Falvello, \& Todorov, 2016). These impressions can be amplified by more temporary facial expressions like furrowed brows (Mondloch, Gerada, Proietti, \& Nelson, 2019), or more permanent aspects of appearance that alter our perceptions of a person's underlying facial features e.g., beardedness (Craig, Nelson, \& Dixson, 2019; Dixson, Lee, Sherlock, \& Talamas, 2017; Dixson \& Vasey, 2012; Nelson, Kennedy-Costantini, Lee, \& Dixson, 2019). Nevertheless, our judgments of others' power from their facial appearance remains heavily influenced by immutable aspects of head shape and bone structure; arising even when a person's facial expressions is demonstrably neutral or they are clean-shaven (Oosterhof \& Todorov, 2008; Todorov, Olivola, Dotsch, \& Mende-Siedlecki, 2015). 
Together, adults' judgements about others' faces and bodies suggest a complex conceptual structure. This structure draws connections between representations of others' behaviors, expressions, and bone structure with different notions of power. Some of the connections between these representations appear straightforward, for example, that someone enacting an expansive pose feels powerful. However, other connections are less likely to be accurate. For example, although people know that being physically strong and having authority are different things, their mental representations of the physical manifestations of these characteristics are remarkably similar (Lukaszewski, Simmons, Anderson, \& Roney, 2016; Murray \& Schmitz, 2011; Sell et al., 2009; Terrizzi, Brey, Shutts, \& Beier, 2019; Toscano et al., 2014; 2016). When attending to others' bodies, people rate strangers with a muscular physique as both physically stronger and more likely to hold a position of authority relative to people that are less muscular (Lukaszewski et al., 2016; Toscano et al., 2016). Additionally, people's judgments of a person's authority from expansive postures appear to be mediated by subjective perceptions of their overall size. People holding an expansive pose appear genuinely larger to observers than those enacting more restrictive poses (Marsh, Blair, Jones, Soliman, \& Blair, 2009a; Marsh, Yu, Schechter, \& Blair, 2009b), and people closely associate overall size with physical strength (Fessler, Holbrook, Pollack, \& HahnHolbrook, 2014; Mattan, Kubota, \& Cloutier, 2017; Murray \& Schmitz, 2011; Yu, Sun, Zhou, Xu, \& Shen, 2017). When attending to others' faces, the specific features (indeed, the same face images) that adults associate with being physically strong also support judgments about having greater authority (Holzleitner \& Perrett, 2016; Oosterhof \& Todorov, 2008; Terrizzi et al., 2019; Toscano et al., 2014; 2016) Thus, there is substantial 
overlap in the aspects of facial and bodily appearance that adults attend to in order to estimate others' social and physical power.

It is surprising that adults infer very different forms of power from the same aspects of physical appearance. First, people often disdain dominant and aggressive forms of social ascendency (Anderson \& Kilduff, 2009; Anderson, Ames, \& Gosling, 2008), so it is not obvious why representations of people's physical power piggy-back on top of representations of others' authority. Second, it is easy to generate examples of people that have authority but who are not physically strong. Thus, it seems clear that physically strong authority figures are not ubiquitous.

Still, the union of these concepts may not be entirely groundless. Some physical features like height are positively associated with professional success and income (Judge \& Cable, 2004), and tallness is surprisingly common to some powerful positions like the US presidency (Stulp, Buunk, Verhulst, \& Pollet, 2012). However, people's expectations about the predictive value of these cues may substantially outweigh their actual utility (Carney, 2020; Hall, Coats, \& LeBeau, 2005). Thus, the real-world associations between strength and authority are complex and possibly more tenuous than our first impressions would suggest. So why are these traits so closely linked in our initial impressions of others' appearance?

\section{Whence adults' intuitions about the physical manifestations of power?}

There are different theoretical perspectives from which people have generated hypotheses about origins of adults' intuitions about the physical manifestations of power. According to one position, these intuitions are cultural constructions that have been 
learned over the course of development (Over and Cook, 2017). Although not intended to explain adults' judgements about powerful appearance per se, this view has been offered as a framework for understanding psychological mappings between specific aspects of others' appearance and specific capabilities and character traits. In the case of power, masculine facial structure and musculature may engender notions of authority and strength because our experiences suggest contingencies among these cues and traits, even if the sources of these contingencies are poorly understood. Some of adults' judgments about powerful appearance are clearly acquired and sustained through experiencedependent cultural learning. For example, some of adults' ability to recognize that specific forms of attire and ornamentation refer to specific institutional roles (Chiao et al., 2008; Chiao, Bordeaux, \& Ambady, 2004) are clearly acquired through a combination of observation and explicit teaching. However, it is less obvious which experiences would support some of people's predictions from their physical appearance, for example, that people possessing stern and masculine facial structure are more likely to be in charge.

Another position argues that our intuitions about powerful appearance arise from an innate (i.e., unlearned) psychology (Lukaszewski et al., 2016; Murray, 2014; Sell et al., 2009; 2010; Sell, Hone, \& Pound, 2012; Toscano et al., 2014). The logic and narrative underlying this perspective is adaptationist in nature: Over the course of our specie's evolutionary history, physically strong and formidable males were uniquely endowed to acquire necessary resources by threatening or inflicting physical costs on competitors. Because these males were uniquely capable of carrying out important leadership activities, they were also more likely to obtain positions of privilege, status, and authority within local groups. Our modern-day judgments of power from expansive 
poses and masculine facial structure reflect the evolved psychological capacities shaped by the predictive value that associations between strength and authority had during these ancestral periods (Lukaszewski et al., 2016; Sell et al., 2009; 2010; Van Vugt \& Grabo, 2015; Zebrowitz \& Zhang, 2011), even if the inferences generated by these adaptations strike us as irrelevant in today's society (Murray, 2014; Murray \& Schmitz, 2011).

Researchers investigating adults' judgments about powerful appearance have tended to argue for the existence of these evolved psychological capacities. Some have done so by appealing to the presence of analogous inferences in non-human primates, preliminary evidence for cross-cultural stability in adults' judgments about powerful appearance, the apparent speed and automaticity of adults' judgments, or some combination of these features to support nativist claims (Murray, 2014; Murray \& Schmitz, 2011; Sell et al., 2009; Van Vugt, 2006; Van Vugt \& Grabo, 2015). While these observations are consistent with the possibility of innate capacities, the specific content and organization of the architecture supporting these judgements has been left unspecified (Over \& Cook, 2018; Terrizzi et al., 2019). Moreover, researchers have tended to discuss the overall pattern of adults' judgments as if these were directly informative about innate psychological content (Lukaszewski et al., 2016; Murray, 2014; Sell et al., 2009; Toscano et al., 2014; Van Vugt \& Grabo, 2015). For example, Lukaszewski et al. (2016) reason that the covariation of adults' judgements of physical strength and authority are indicative of evolved adaptations specifically designed to take cues of human strength as input and produce judgments about authority status as output. However, more specific information about these "adaptations" is absent and other 
(untested) explanations remain viable. Because of this, natural questions about the underlying characteristics of this putatively innate psychology arise.

One question concerns the ontogenetic status of the concepts that correspond to the traits and capabilities that we ascribe to others. The nativist position described above appears to require that our mature concepts of physical strength and normative authority are entirely innate. Is there any evidence to suggest that they are? Another question concerns ontogenetic status of the representations of appearance that we imbue with social meaning. Do we also possess innate representations containing specific information about the faces and bodies that adults view as powerful? Finally, we must consider the ontogenetic origins of the specific correspondences that adults are apt to detect between and among these different representations. Adults' tendency to detect very specific and counterintuitive appearance-to-power correspondences (e.g., viewing muscular people as authorities) has provided the empirical impetus for nativist claims. But adults have many years of experience upon which to develop and refine these associations. Thus, the logic linking adults' judgments to innate mental content appears tenuous.

\section{The Contribution of Developmental Psychology}

The social experiences of infants and young children are much more limited than those of adults. Thus, their social responses and judgments about the different aspects of appearance that adults' view as powerful may be more directly informative about the origins of adults' intuitions. Specifically, discovering the ages at which some of adults' intuitions first emerge may shed light on the quantity and quality of experiences that are 
relevant for their manifestation. Moreover, investigating young children's judgments across multiple ages may reveal developmental patterns that are more or less consistent with the presence of innate capacities. For example, if adult's singular judgments about powerful appearance are straightforward outputs of an innate psychology, we would expect young children to exhibit adult-like intuitions about the same cues from very early in development. Moreover, if the overall pattern of appearance-to-power correspondences that adults detect are determined by innate structure, young children should detect the same correspondences and these intuitions ought to remain stable across the lifespan. In contrast, if adults' mature judgments about powerful appearance are heavily influenced by experience, we might uncover the timeline along which young children first discover the power-to-appearance correspondences that adults expect, and the changing pattern of these intuitions across the lifespan. Of course, more complex developmental patterns are also possible. Perhaps some of adults' judgements about powerful appearance are more closely related to innate mental content than others. If so, young children may initially share only some of adults' intuitions (e.g., that stern faces are "strong"), while others are acquired later (e.g., that stern faces are "in charge"). But the studies necessary for answering these questions are best pursued by engaging young participants, as knowing the specific ages at which adult-like judgments first emerge can help constrain our theorizing about the origins of our mature thinking about the physical manifestations of power.

As it turns out, there has been a recent resurgence in developmental psychologists' interest in young children's earliest intuitions about both the behavioral and physical manifestations of power. In this area of study, researchers have primarily 
focused on children's judgments about which of two people is more powerful on the basis of their behaviors within third-party interactions. However, researchers have also begun to investigate young children's thinking about the physical manifestations of power. Do young children's judgments reveal the interwoven conceptual structure suggested by adults' judgments? As summarized below, the picture that emerges from this body of work is complex: There are aspects of both continuity and discontinuity between young children's and adults' thinking. These findings force us to explore more complex hypotheses about the origins of adults' intuitions about the physical manifestations of power.

\section{Infants' earliest understanding of the physical manifestations of power}

The complexity of human sociality makes it unlikely that we must each discover the entire structure of our social world anew. Instead, we likely possess innate mental representations that allow us to either recognize or attend to the occurrence of specific social relationships upon first encountering them (Carey, 2009; Spelke \& Skerry, 2012; Fiske, 1992). These mental representations may include information that helps young members of our species recognize and navigate instances of relative power (Pun, Birch, \& Baron, 2017; Thomsen, 2019; Thomsen \& Carey, 2015). Exploring the existence, content, and structure of these early representations is fruitfully pursued by investigating the social-cognitive development of preverbal infants. After all, their social behaviors are necessarily guided by representations that do not depend on the same social experiences had by older children and adults. 
Infants' earliest documented sensitivities to relative power are best understood as intuitions about the relative formidability of two agents. By at least 9 to 13 months of age, infants anticipate that an imminent right-of-way conflict will be settled in favor of the larger of two agents (Thomsen, Frankenhuis, Ingold-Smith, \& Carey, 2011) Slightly younger 6- to 12-month-olds use similar principles to distinguish the relative formability of two groups; anticipating that right-of-way conflicts will be settled in favor of the agent belonging to the larger of two parties (Pun, Birch, \& Baron, 2016). Older 15-month-old infants appear to assume that an agent who prevails in a single physical conflict over a disputed resource will continue to prevail or receive rewards following similar conflicts in the future (Enright, Gweon, \& Sommerville, 2017; Gazes \& Hampton, 2015; Mascaro \& Csibra, 2012; 2014).

Infants' expectations when viewing these displays accord well with the view that humans possess evolved and specialized capacities for assessing physical strength (e.g., Sell et al., 2009). Indeed, developmental psychologists have interpreted the results of these studies along similar lines (Pun, Birch, \& Baron, 2017; Thomas et al., 2018; Thomsen, 2019; Thomsen \& Carey, 2015). However, these displays did not contain behaviors that are integral to older children's and adults' understanding of strength - e.g., lifting capacity, or one agent inflict physical damage to another one. In addition, these displays presented infants with animated characters whose "bodies" are comprised of geometric shapes, and puppets that only superficially resemble people. On the one hand, these methods are necessary for young participants and crucial to control for low-level morphological differences between characters that would contaminate the internal logic of these specific studies. On the other hand, these methodological choices limit our 
ability to ascertain whether infants' attentional responses in these contexts extend to interactions involving humans, when infants become sensitive to more human-specific cues to physical strength, and whether the notion of relative power invoked by these behaviors and overall size are continuous with the concept of strength possessed by older children and adults. Thus, the term formidability may be most appropriate to describe infants' competencies as this term is reasonably interpreted as agnostic about the specific capabilities that might underly an agents' power.

Despite these concerns, these studies have employed a range of ingenious control conditions which indicate that infants' expectations about formidable agents are genuinely social in nature: These expectations do not arise when characters are stripped of cues like eyes which indicate that they are animate agents or when two agents' goals are not in conflict with one another. Thus, these studies suggest that infants' expectations are supported by mental representations relating some types of behaviors and relative body size with outcomes suggesting of relative power when conflicting goals emerge between two agents.

There is only a single study assessing infants' responses to more human-specific aspects of powerful appearance (Jessen \& Grossmann, 2016). As an indication of infants' sensitivity to variation in facial structure, 7-month-olds prefer to look at faces that adults judge as "trustworthy" relative to faces that adults judge as "untrustworthy".

Additionally, this visual preference for trustworthy faces was accompanied by unique neural processing of these images. Thus, there are at least two distinct signatures of infants' sensitivity to variation in facial structure. In contrast, the infants recruited to this study did not also exhibit a visual preference for faces either high or low in adults' ratings 
of "dominance" and physical strength, nor did these images trigger differential neural responses. Thus, while infants are clearly sensitive to some aspects of facial structure that adults are sensitive to, we cannot be sure whether - or to what extent - the responses documented in the infant studies described earlier are supported by representations that are similar to those supporting adults' explicit judgments about powerful appearance.

\section{Children's developing judgments about the behavioral manifestations of authority and strength}

By the time that young children enter preschool, they mentally represent and understand many of the behavioral manifestations of power. They are also capable of utilizing this knowledge to identify which of two people is "in charge" within third-party interactions. For children, people that are in charge establish rules and gives orders (Bernard et al., 2016; Charafeddine et al., 2016), control resources (Charafeddine, Mercier, Clément, Kaufmann, Berchtold, Reboul, \& Van der Henst, 2014a; Gülgöz \& Gelman, 2016), are less likely to help in low-cost situations (Terrizzi, Woodward, \& Beier, 2020), are more likely to be imitated by others (Over \& Carpenter, 2014), and generally influence how other people behave in their presence (Chudek, Heller, Birch, \& Henrich, 2011; Gülgöz \& Gelman, 2016; Zhao \& Kushnir, 2017).

Young children also mentally represent and understand some of the behavioral manifestations of physical strength. For example, 6- to 8-year-olds use verbal descriptions about the relative strength of two characters to anticipate who will prevail in a physical conflict (Pietraszewski \& Shaw, 2015). Younger preschool-age children think that a person capable of lifting a heavy object is "strong" and that that these people will 
be able to lift other heavy objects in the future (Fusaro, Corriveau, \& Harris, 2011). At this same age, children also recruit and endorse physically strong characters for tasks requiring strength (Hermes, Behne, \& Rakoczy, 2015; Hermes, Behne, Bich, Thielert, \& Rakoczy, 2017; Hermes et al., 2016; Paulus \& Moore, 2011). Even toddlers appear sensitive to some demonstrations of strength, and negatively evaluate an agent that physically dominates someone else to achieve their own goals (Thomas, Thomsen, Lukowski, Abramyan, \& Sarnecka, 2018). These observations of children's judgments about authority and strength suggest that within this broad developmental period, their understanding of these characteristics may be more sophisticated than infants' understanding of formidability and resembles adults' understanding in important respects.

Focusing on the specific ages at which children become sensitive to different behavioral indications of power reveals that this knowledge does not emerge in a fixed fashion. That is, children are still discovering how these characteristics manifest in others' actions. For example, there is mixed evidence about whether children younger than 6 years view establishing norms as an indication of authority (Brey \& Shutts, 2015; Gülgöz \& Gelman, 2016), and 5-year-olds view the most imitated member of a group as the person that is in charge, but slightly younger 4-year-olds do not have clear intuitions about imitated group members (Over \& Carpenter, 2014).

During this same developmental period, children also appear to refine their understanding of both the scope and social relevance of physical strength. For example, preschool-age children ascribe traits like competency to strong characters even though adults do not make similar inferences (Fusaro et al., 2011). Children this age also have less consistent intuitions about the relevance of physical strength for some tasks relative 
to adults (Hermes et al., 2016), and children under 3 do not consistently endorse strong characters for tasks that clearly require the ability to lift heavy objects (Paulus \& Moore, 2011).

Many of these studies employ similar methods and define authority and strength in similar ways. Thus, the age-related changes that they reveal are not easily explained by low-level methodological issues. Rather, these studies highlight that while some of young children's understanding of the behavioral manifestations of authority and strength resemble adults' understanding, they are still refining their understanding of how these characteristics manifest in others' interactions and behaviors. Nevertheless, ascertaining the causal factors underlying others' behaviors may be challenging for children, and they may show a greater facility at either identifying or discussing the physical manifestations of authority and strength. Like adults, do young children expect that authority figures carry themselves differently than people low in authority status, or associate some aspects of appearance with both authority and strength?

\section{Children's developing judgments about the physical manifestations of authority and strength}

There are materially fewer studies investigating children's intuitions about the physical manifestations of power. However, this emerging body of work establishes important aspects of continuity between children's and adults' judgments about powerful appearance. Regarding authority, 4- to 6-year-old children are more likely to interpret people enacting expansive poses and men with masculine facial features as being "in charge" (Brey \& Shutts, 2015; Charafeddine, Mercier, Clément, Kaufmann, Berchtold, 
Reboul, \& Van der Henst, 2014b; Keating \& Bai, 1986; Terrizzi et al., 2019). At similar ages, children also infer related concepts like being "proud" from expansive poses (Nelson \& Russell, 2015; Tracy, Robins, \& Lagattuta, 2005), and view bearded males as older than men that are clean-shaven (Nelson et al., 2019). Regarding strength, by at least 3 years of age, children label people with large, articulated muscles as "strong" (Nelson et al., 2019; Paulus \& Moore, 2011; Terrizzi et al., 2019), and older 4- to 6-year-old children interpret people enacting expansive poses and men with mature, masculine facial structure as "strong" (Terrizzi et al., 2019). At similar ages, like adults, children also view bearded males as being stronger and more masculine than males that are cleanshaven (Nelson et al., 2019).

This body of work also documents instances of disagreement and discontinuity. Children and adults do not always agree about the type of power indicated by a person's appearance. For example, 4- to 6-year-olds label someone enacting an expansive pose as strong but adults do not appear to share this intuition (Nelson et al., 2019; Terrizzi et al., 2019). Thus, children appear to infer a wider range of power-relevant concepts from some aspects of appearance that adults view as powerful. The underlying reasons for this specific difference between children and adults' judgments are not clear. One possibility is that children and adults differ in how they reason about the size-enhancing aspects of expansive posture. Of course, adults may simply appreciate that people who are physically weak are capable of adopting powerful poses. However, as mentioned earlier, adults' also judge that characters who adopt expansive poses are actually larger than characters that adopt more restrictive poses (Marsh, Blair, Jones, Soliman, \& Blair, 2009a; Marsh, Yu, Schechter, \& Blair, 2009b). Although we do not know at what ages 
these perceptual effects first arise, it is possible that children also experience expansive poses as actually larger. If so, adults' may simply be more capable of avoiding some of the inferences that fall out of their perceptual experiences of others' behaviors whereas children might struggle in this regard.

This body of work also documents instances of disagreement and discontinuity within childhood, as children at different ages do not always agree about the type of power indicated by a person's appearance. For example, 4- to 6-year-old children detect a greater number of correspondences between appearance and power than younger children do. Whereas 4- to 6-year-old children associate both expansive poses and masculine facial structure with both authority and strength, slightly younger 3-year-olds only associate expansive poses with strength (Marsh et al., 2009b; Terrizzi et al., 2019). This difference between younger and older children's intuitions is not easily explained by a misunderstanding about what it means to be either "strong" or to be "in charge". As discussed earlier, 3-year-olds' understanding of these concepts is similar to older children's understanding. Moreover, 3-year-olds have applied these labels to others' behaviors in interpretable way across various studies (Brey \& Shutts, 2015; Charafeddine et al., 2016; Charafeddine, Mercier, Clément, Kaufmann, Berchtold, Reboul, \& Van der Henst, 2014b; Gülgöz \& Gelman, 2016; Lourenco, Bonny, \& Schwartz, 2016). Thus, 3and 4-year-olds appear to differ in the specific appearance-to-power correspondences that they detect, though it is not clear what specific aspects of development underly these differences.

With respect to faces, children younger than 4 may simply not be sensitive to the same aspects of facial structure that older children and adults are sensitive to. In favor of 
this possibility is the observation that 3-year-olds do not have clear intuitions about either the relative strength or authority of faces that differ in terms of adults' judgments of "dominance" (Terrizzi, et al., 2019). However, opposing this possibility, studies utilizing identical face images have observed 3- and 4-year-old children labelling these characters as "mean" (Charlesworth, Hudson, Cogsdill, Spelke, \& Banaji, 2019; Cogsdill, Todorov, Spelke, \& Banaji, 2014). Thus, 3-year-olds may notice the same differences in facial structure that older children do, but only infer relative meanness (and not relative power) from these differences. Our ability to adjudicate between these explanations is limited. For example, these latter reports have pooled the responses of children across this 3- to 4year-old age range, so it is not clear if there are meaningful differences between the responses of older and younger children. This analytical approach may have been appropriate within the context of these individual studies; however, they highlight that we know very little about age-related changes across periods of less than a year, and there are currently no longitudinal studies assessing children's developing judgments about powerful appearance.

Regardless of these specific analytic considerations, there are other methodological features of these studies that may exacerbate age-related differences in children's responding. For example, the majority of studies discussed above have required young participants to engage in a question-and-answer style interview session with an adult experimenter. Although these sessions are designed to be developmentally appropriate and engaging for children, it is possible that the developmental trends discussed above are at least partially dependent on age-related differences in children's ability to participate in these interactions. If so, tasks that reduce the requirement to 
provide verbal responses might reveal intuitions at younger ages that more closely match those of older children and adults.

Following this logic, Terrizzi and colleagues (2019) engaged 3- to 6-year-old children in a non-verbal task that allowed them to match cut-outs of high- and low-power faces with cut-outs of bodies in expansive or restrictive poses. These researchers reasoned that if children detected power-relevant correspondences between these cues, they should affix images of masculinized faces to images of expansive poses and images of less masculinized faces to images of restrictive poses. In this task, 4- to 6-year-old children overwhelmingly affixed these images in the anticipated fashion. However, slightly younger 3-year-old children appeared to affix these images randomly. Thus, 3year-old children do appear to detect power-relevant differences in faces. At the very least, either the format or content of the differences that 3-year-olds see in these faces is not easily aligned with what they see in postures. These tendencies closely match the pattern of inferences suggested by children's verbal responses. Thus, we can be fairly confident that the age-related changes revealed by these very different measures indicate genuine conceptual change in the appearance-to-power correspondences that children are capable of detecting at different ages.

\section{Conclusion \& Future Directions}

We have only begun learning about how infants and young children think about the physical manifestations of power. We know that preverbal infants are sensitive to instances of relative power, but it is not clear whether they are sensitive to domains of power beyond those of relative formidability. Additionally, it is unknown whether infants 
are capable of discerning the relative power of other humans using either the same, or a unique set of cues that allow them to discern the relative power of animated agents. Later in development, preschool age children appreciate multiple forms of power and some of power's physical manifestations. However, neither their sensitivity to the specific cues that adult's find powerful, nor their inferences from these cues develop uniformly. Between 4 and 6 years of age, children begin to exhibit patterns of inference that are similar to adults' judgments. However, the power-appearance correspondences they detect are more promiscuous than those detected by adults and will continue to change as children grow older. Thus, the conceptual structure suggested by adults' judgments does not capture how children initially think about powerful appearance. As a consequence, it is unlikely that adults' judgments are straightforward outputs of an innate psychological structure. Infants' sensitivities are consistent with the presence of remarkably early abstract mental representations of power and powerful appearance. However, but we must explore more complex hypotheses about the mechanisms that link these early representations with adults' judgments. Generating these hypotheses will involve a deeper consideration of the developmental patterns linking multiple points in development, as well as attempts to assess change across time points not already explored. In addition to adopting this developmental perspective, researchers must confront recent findings demonstrating that individual differences in people's social experiences and attitudes greatly influences their mental representations and social perceptions of others.

Focusing on describing a more complete developmental picture, people navigate social hierarchies at every stage of life. However, the needs and motivations that we bring 
to these engagements change over time. These changes may significantly alter the salience and meaning that we ascribe to different types of social information. Thus, it would be helpful if researchers adopted research strategies that more fully engaged these dynamics. One way to do this is to conduct the type of work already described in this review by assessing for potential change in people's intuitions about powerful appearance over time. However, there are significant gaps in our understanding of these changes between both infancy and childhood and between childhood and adolescence.

Adolescence in particular reflects a time when young people undergo significant emotional and motivational changes which appear to heavily influence aspects of social functioning and perception (Kilford, Garrett, \& Blakemore, 2016). A striking example of this comes from studies documenting changes in adolescents' processing of facial information (Motta-Mena \& Scherf, 2016; Picci \& Scherf, 2016; Scherf, Behrmann, \& Dahl, 2012). Pre-pubescent children are generally more dependent on caregivers than older adolescent youth and, thus, preferentially attend to and process facial features that likely identify potential caregivers - i.e., adult and female facial characteristics, (Picci \& Scherf, 2016). However, these abilities become increasingly peer-centric after pubertal onset at which point young people show a marked decline in their ability to discriminate adult faces and a greater facility at discriminating faces of same age peers (Picci \& Scherf, 2016). Moreover, as children enter their teenage years, impressions that heavily influence our desire to engage with specific individuals (e.g., attractiveness and trustworthiness) become increasingly correlated in young people's judgments of others' facial appearance (Ma \& Luo, 2016). Pubertal age also seems to enhance young people's sensitivity to emotional expressions like anger (Motta-Mena \& Scherf, 2016; Picci \& 
Scherf, 2016; Scherf et al., 2012). Together, these changes very likely reflect a motivational shift from identifying opportunities for receiving care to gaining independence and mastery within peer-interactions during this developmental period. However, there is limited information about adolescents' impressions of either expansive poses or masculinized facial structure. Thus, studies of just this sort are necessary to more fully assess the developmental processes connecting children's and adults' judgments about powerful appearance.

A useful model for this type of work has been conducted by Nelson and colleagues (2019) who assessed young people's developing impressions of beardedness between childhood and adulthood. Between early childhood and adolescence, children increasingly associate power-relevant traits like masculinity and strength with bearded males. While these tendencies seem to become fairly fixed by the early teenage years, there are further developments in other types of judgments by adolescence. After 13 years of age, teenagers (many of whom have likely experienced pubertal onset) increasingly viewed bearded males as more attractive than clean-shaven males. These patterns highlight that adolescence marks an important developmental shift in the motivational and conceptual framework from which social judgments about others' appearance arise. Thus, it will be important for future work to more fully characterize the nature of young people's judgements from different aspects of appearance across this age range. Doing so may help clarify specific differences between children and adults' judgments (e.g., that expansive poses are "strong"), and whether these changes reflect shifts in young people's thinking about specific aspects of appearance, traits like authority and strength, or some combination of these factors. 
In addition to developing a more complete picture of people's judgments across the lifespan, we must strive to understand how individual differences in people's social experiences shape the social meaning that they ascribe to others' appearance. For example, Black and White North American adults possess different mental representations of faces belonging to police officers (Lloyd, Sim, Smalley, Bernstein, \& Hugenberg, 2020). When Black and White adults are asked to construct images of officer faces, naïve observers rate the images generated by Black adults as more "dominant" and "negative" than those generated by White adults. A proximal source of these differences are the diverging experience-dependent attitudes that Black and White North Americans have about law enforcement and institutional authority (Berthelot, McNeal, \& Baldwin, 2018; Brunson \& Weitzer, 2009; Carr, Napolitano, \& Keating, n.d.; J. M. Lee, Steinberg, \& Piquero, 2010). Indeed, more formal models of social perception have begun describing how stereotypic expectations of others based on social identities (e.g., race) and social roles (e.g., being a police officer) influence social perception at many levels (Freeman \& Ambady, 2011; Hehman, Stolier, Freeman, Flake, \& Xie, 2019; Hehman, Sutherland, Flake, \& Slepian, 2017; Lloyd et al., 2020; Stolier, Hehman, \& Freeman, $2018 ; 2020)$. These expectations shape how we interpret both inherent and momentary aspects of facial appearance (Collova, Sutherland, \& Rhodes, 2019; Kunstman, Tuscherer, Trawalter, \& Lloyd, 2016; Lloyd, Hugenberg, McConnell, Kunstman, \& Deska, 2017a; Lloyd, Kunstman, Tuscherer, \& Bernstein, 2017b; Sutherland, Rhodes, Burton, \& Young, 2019). Together, these studies strongly support a link between people's intuitions about powerful appearance and individual differences in powerrelevant experiences. Thus, the view that adults' judgments about powerful appearance 
are either immune to experience or inevitable based on evolved capacities does not conform to our most current understanding of the social and psychological processes that give rise to our impressions of others. As a consequence, researchers must be cognizant that what might initially look like universality in adults' intuitions about powerful appearance may rest in part homogeneity in psychological structure, but might also reflect homogeneity in the power-relevant experiences of WEIRD study samples (Henrich, Heine, \& Norenzayan, 2010; Nielsen \& Haun, 2015). To better ascertain if this is so, it will be important for researchers to continue incorporating culturally relevant context to experimental studies to reveal both subject (Hehman et al., 2017) and group level (Jones, et al., 2018) variability in people's judgements about powerful appearance.

At least one concrete target for future developmental work emerges when considering a final aspect of adults' mature intuitions about powerful appearance. Adults do not interpret appearance-based cues to power in consistent ways. For example, adults more closely associate physical strength with authority when looking at males than when looking at females (Lukaszewski et al., 2016; Toscano et al., 2016). At this time, we can only speculate about the social and cultural experiences that could give rise to these tendencies as studies with children have tended to employ entirely male or genderambiguous characters. A single study has compared similar gendered representations in children from a country with explicit norms favoring gender equity - e.g., Norway, and a country were gender inequality is more tolerated - e.g., Lebanon, (Charafeddine et al., 2020). Both populations of children generally assumed that men would be more likely to behave as if they were more powerful than women. These intuitions emerged by 4 years of age. Thus, investigating the development of these gendered representations and 
determining the extent to which children's and adults' judgments about powerful appearance reflect the internalization of a patriarchal reality are both concrete and consequential domains of inquiry for future research. 


\section{References}

Anderson, C., \& Kilduff, G. J. (2009). The Pursuit of Status in Social Groups. Current Directions in Psychological Science, 18(5), 295-298. http://doi.org/10.1111/j.14678721.2009.01655.x

Anderson, C., Ames, D. R., \& Gosling, S. D. (2008). Punishing Hubris: The Perils of Overestimating One's Status in a Group. Personality and Social Psychology Bulletin, 34(1), 90-101. http://doi.org/10.1177/0146167207307489

Bernard, S. P., Castelain, T., Mercier, H., Kaufmann, L., Van der Henst, J.-B., \& Clément, F. (2016). The boss is always right: Preschoolers endorse the testimony of a dominant over that of a subordinate. Journal of Experimental Child Psychology, 111. http://doi.org/10.1016/j.jecp.2016.08.007

Berthelot, E. R., McNeal, B. A., \& Baldwin, J. M. (2018). Relationships between Agency-Specific Contact, Victimization Type, and Trust and Confidence in the Police and Courts, 1-25. http://doi.org/10.1007/s12103-018-9434-x

Brey, E., \& Shutts, K. (2015). Children Use Nonverbal Cues to Make Inferences About Social Power. Child Development, 86(1), 276-286.

http://doi.org/10.1111/cdev.12334

Brunson, R. K., \& Weitzer, R. (2009). Police Relations with Black and White Youths in Different Urban Neighborhoods. Urban Affairs Review, 44(6), 858-885. http://doi.org/10.1177/1078087408326973

Burgoon, J. K., Buller, D. B., Hale, J. L., \& Turck, M. A. (1984). Relational Messages Associated with Nonverbal Behaviors. Human Communication Research, 10(3), 351-378. http://doi.org/10.1111/j.1468-2958.1984.tb00023.x 
Carey, S. (2009). The Origin of Concepts. Oxford University Press. http://doi.org/10.1093/acprof:oso/9780195367638.001.0001

Carney, D. R. (2020). The Nonverbal Expression of Power, Status, and Dominance. Current Opinion in Psychology, 1-30. http://doi.org/10.1016/j.copsyc.2019.12.004

Carr, P. J., Napolitano, L., \& Keating, J. (n.d.). We never call the cops and here is why: A qualitative examination of legal cynicism in three Philadelphia neighborhoods. Developmental Psychology, 45(2), 445-480.

Charafeddine, R., Mercier, H., Clément, F., Kaufmann, L., Berchtold, A., Reboul, A., \& Van der Henst, J.-B. (2014a). How Preschoolers Use Cues of Dominance to Make Sense of Their Social Environment. Journal of Cognition and Development, 16(4), 587-607. http://doi.org/10.1080/15248372.2014.926269

Charafeddine, R., Mercier, H., Clément, F., Kaufmann, L., Berchtold, A., Reboul, A., \& Van der Henst, J.-B. (2014b). How Preschoolers Use Cues of Dominance to Make Sense of Their Social Environment. Journal of Cognition and Development, 16(4), 587-607. http://doi.org/10.1080/15248372.2014.926269

Charafeddine, R., Mercier, H., Clément, F., Kaufmann, L., Reboul, A., \& Van der Henst, J.-B. (2016). Children's allocation of resources in social dominance situations. Developmental Psychology, 52(11), 1843-1857. http://doi.org/10.1037/dev0000164 Charafeddine, R., Zambrana, I. M., Triniol, B., Mercier, H., Clément, F., Kaufmann, L., et al. (2020). How Preschoolers Associate Power with Gender in Male-Female Interactions: A Cross-Cultural Investigation Rawan Charafeddine, Imac Maria Zambrana, Benoit Triniol, Hugo Mercier, Fabrice Clément, Laurence Kaufmann, Anne Reboul, et al., 1-23. http://doi.org/10.1007/s11199-019-01116-x 
Charlesworth, T. E. S., Hudson, S.-K. T. J., Cogsdill, E. J., Spelke, E. S., \& Banaji, M. R. (2019). Children use targets' facial appearance to guide and predict social behavior. Developmental Psychology, 1-15. http://doi.org/10.1037/dev0000734

Chiao, J. Y., Adams, R. B., Tse, P. U., Lowenthal, W. T., Richeson, J. A., \& Ambady, N. (2008). Knowing Who's Boss: fMRI and ERP Investigations of Social Dominance Perception. Group Processes \& Intergroup Relations, 11(2), 201-214. http://doi.org/10.1177/1368430207088038

Chiao, J. Y., Bordeaux, A. R., \& Ambady, N. (2004). Mental representations of social status. Cognition, 93(2), B49-B57. http://doi.org/10.1016/j.cognition.2003.07.008

Chudek, M., Heller, S., Birch, S., \& Henrich, J. (2011). Prestige-biased cultural learning: bystander's differential attention to potential models influences children's learning. Evolution and Human Behavior, 1-12. http://doi.org/10.1016/j.evolhumbehav.2011.05.005

Cogsdill, E. J., Todorov, A. T., Spelke, E. S., \& Banaji, M. R. (2014). Inferring Character From Faces: A Developmental Study. Psychological Science, 25(5), 1132-1139. http://doi.org/10.1177/0956797614523297

Collova, J. R., Sutherland, C. A. M., \& Rhodes, G. (2019). Testing the functional basis of first impressions: Dimensions for children's faces are not the same as for adults' faces. Journal of Personality and Social Psychology, 117(5), 900-924. http://doi.org/10.1037/pspa0000167

Craig, B. M., Nelson, N. L., \& Dixson, B. J. (2019). Sexual Selection, Agonistic Signaling, and the Effect of Beards on Recognition of Men's Anger Displays. Psychological Science, 30(5), 728-738. http://doi.org/10.1177/0956797619834876 
Dixson, B. J. W., Lee, A. J., Sherlock, J. M., \& Talamas, S. N. (2017). Beneath the beard: do facial morphometrics influence the strength of judgments of men's beardedness? Evolution and Human Behavior, 38(2), 164-174. http://doi.org/10.1016/j.evolhumbehav.2016.08.004

Dixson, B. J., \& Vasey, P. L. (2012). Beards augment perceptions of men's age, social status, and aggressiveness, but not attractiveness. Behavioral Ecology, 23(3), 481490. http://doi.org/10.1093/beheco/arr214

Durkee, P. K., Lukaszewski, A. W., \& Buss, D. M. (2019). Pride and shame_Key components of a culturally universal status management system. Evolution and Human Behavior, 1-0. http://doi.org/10.1016/j.evolhumbehav.2019.06.004

Spelke, E.S. \& Skerry, A. E. (2012). Core Social Cognition. In Navigating the Social World (pp. 11-16). Oxford University Press. http://doi.org/10.1093/acprof:oso/9780199890712.003.0003

Enright, E. A., Gweon, H., \& Sommerville, J. A. (2017). "To the victor go the spoils": Infants expect resources to align with dominance structures. Cognition, 164, 8-21. http://doi.org/10.1016/j.cognition.2017.03.008

Fessler, D. M. T., Holbrook, C., Pollack, J. S., \& Hahn-Holbrook, J. (2014). Stranger danger: Parenthood increases the envisioned bodily formidability of menacing men. Evolution and Human Behavior, 35(2), 109-117. http://doi.org/10.1016/j.evolhumbehav.2013.11.004

Fiske, A. P. (1992). The four elementary forms of sociality: Framework for a unified theory of social relations. Psychological Review, 99(4), 689-723. http://doi.org/10.1037/0033-295x.99.4.689 
Foulsham, T., Cheng, J. T., Tracy, J. L., Henrich, J., \& Kingstone, A. (2010). Gaze allocation in a dynamic situation: Effects of social status and speaking. Cognition, 117(3), 319-331. http://doi.org/10.1016/j.cognition.2010.09.003

Freeman, J. B., \& Ambady, N. (2011). A dynamic interactive theory of person construal. Psychological Review, 118(2), 247-279. http://doi.org/10.1037/a0022327

Fusaro, M., Corriveau, K. H., \& Harris, P. L. (2011). The good, the strong, and the accurate: Preschoolers' evaluations of informant attributes. Journal of Experimental Child Psychology, 110(4), 561-574. http://doi.org/10.1016/j.jecp.2011.06.008

Gazes, R. P., \& Hampton, R. R. (2015). Transitive inference of social dominance by human infants. Developmental Science, n/a-n/a. http://doi.org/10.1111/desc.12367 Gülgöz, S., \& Gelman, S. A. (2016). Who's the Boss? Concepts of Social Power Across Development. Child Development, 1-23. http://doi.org/10.1111/cdev.12643

Hall, J. A., Coats, E. J., \& LeBeau, L. S. (2005). Nonverbal Behavior and the Vertical Dimension of Social Relations: A Meta-Analysis. Psychological Bulletin, 131(6), 898-924. http://doi.org/10.1037/0033-2909.131.6.898

Hall, J. A., Horgan, T. G., \& Murphy, N. A. (2019). Nonverbal Communication. Annual Review of Psychology, 70(1), 271-294. http://doi.org/10.1146/annurev-psych010418-103145

Hecht, M. A., \& LaFrance, M. (1998). License or Obligation to Smile: The Effect of Power and Sex on Amount and Type of Smiling. Personality and Social Psychology Bulletin, 24(12), 1332-1342. http://doi.org/10.1177/01461672982412007

Hehman, E., Stolier, R. M., Freeman, J. B., Flake, J. K., \& Xie, S. Y. (2019). Toward a comprehensive model of face impressions: What we know, what we do not, and 
paths forward. Social and Personality Psychology Compass, 38(7), e12431-16. http://doi.org/10.1111/spc3.12431

Hehman, E., Sutherland, C. A. M., Flake, J. K., \& Slepian, M. L. (2017). The unique contributions of perceiver and target characteristics in person perception. Journal of Personality and Social Psychology, 113(4), 513-529.

http://doi.org/10.1037/pspa0000090

Henrich, J., Heine, S. J., \& Norenzayan, A. (2010). Most people are not WEIRD. Nature, 466(7302), 29-. http://doi.org/10.1038/466029a

Hermes, J., Behne, T., \& Rakoczy, H. (2015). The role of trait reasoning in young children's selective trust. Developmental Psychology, 51(11), 1574-1587. http://doi.org/10.1037/dev0000042

Hermes, J., Behne, T., Bich, A. E., Thielert, C., \& Rakoczy, H. (2017). Children's selective trust decisions: rational competence and limiting performance factors. Developmental Science, 1-12. http://doi.org/10.1111/desc.12527

Hermes, J., Behne, T., Studte, K., Zeyen, A.-M., Gräfenhain, M., \& Rakoczy, H. (2016). Selective Cooperation in Early Childhood - How to Choose Models and Partners. Plos One, 11(8), e0160881-13. http://doi.org/10.1371/journal.pone.0160881

Holland, E., Wolf, E. B., Looser, C., \& Cuddy, A. (2017). Visual attention to powerful postures: People avert their gaze from nonverbal dominance displays. Journal of Experimental Social Psychology, 68, 60-67. http://doi.org/10.1016/j.jesp.2016.05.001 
Holzleitner, I. J., \& Perrett, D. I. (2016). Perception of strength from 3D faces is linked to facial cues of physique. Evolution and Human Behavior, 37(3), 217-229. http://doi.org/10.1016/j.evolhumbehav.2015.11.004

Jessen, S., \& Grossmann, T. (2016). Neural and Behavioral Evidence for Infants' Sensitivity to the Trustworthiness of Faces. Journal of Cognitive Neuroscience, 1-9. http://doi.org/10.1162/jocn_a_00999

Jones, B. C., DeBruine, L., Flake, J. K., Aczel, B., \& Adamkovic, M. (2018). To Which World Regions Does the Valence-Dominance Model of Social Perception Apply? Judge, T. A., \& Cable, D. M. (2004). The Effect of Physical Height on Workplace Success and Income: Preliminary Test of a Theoretical Model. Journal of Applied Psychology, 89(3), 428-441. http://doi.org/10.1037/0021-9010.89.3.428

Keating, C. F., \& Bai, D. L. (1986). Children's Attributions of Social Dominance from Facial Cues. Child Development, 57(5), 1269-1276. http://doi.org/10.2307/1130449?ref=searchgateway:99dfcc0055c7d275c663cc5b94e61ade Keating, C. F., Mazur, A., \& Segall, M. H. (1977). Facial Gestures Which Influence the Perception of Status. Sociometry, 40(4), 374-378.

http://doi.org/10.2307/3033487?ref=-searchgateway:64389cd65917203fb3b74b95560162bc

Kilford, E. J., Garrett, E., \& Blakemore, S.-J. (2016). The development of social cognition in adolescence: An integrated perspective. Neuroscience and Biobehavioral Reviews, 70, 106-120. http://doi.org/10.1016/j.neubiorev.2016.08.016 
Kunstman, J. W., Tuscherer, T., Trawalter, S., \& Lloyd, E. P. (2016). What Lies Beneath? Minority Group Members' Suspicion of Whites' Egalitarian Motivation Predicts Responses to Whites' Smiles. Personality and Social Psychology Bulletin, 42(9), 1193-1205. http://doi.org/10.1177/0146167216652860

Lee, J. M., Steinberg, L., \& Piquero, A. R. (2010). Ethnic identity and attitudes toward the police among African American juvenile offenders. Journal of Criminal Justice, 38(4), 781-789. http://doi.org/10.1016/j.jcrimjus.2010.05.005

Lloyd, E. P., Hugenberg, K., McConnell, A. R., Kunstman, J. W., \& Deska, J. C. (2017a). Black and White Lies: Race-Based Biases in Deception Judgments. Psychological Science, 28(8), 1125-1136. http://doi.org/10.1177/0956797617705399

Lloyd, E. P., Kunstman, J. W., Tuscherer, T., \& Bernstein, M. J. (2017b). The Face of Suspicion. Social Psychological and Personality Science, 8(8), 953-960. http://doi.org/10.1177/1948550617699251

Lloyd, E. P., Sim, M., Smalley, E., Bernstein, M. J., \& Hugenberg, K. (2020). Good Cop, Bad Cop: Race-Based Differences in Mental Representations of Police. Personality and Social Psychology Bulletin, 014616721989856-14. http://doi.org/10.1177/0146167219898562

Lourenco, S. F., Bonny, J. W., \& Schwartz, B. L. (2016). Children and Adults Use Physical Size and Numerical Alliances in Third-Party Judgments of Dominance. Frontiers in Psychology, 6(e5707), 375-10. http://doi.org/10.3389/fpsyg.2015.02050 Lukaszewski, A. W., Simmons, Z. L., Anderson, C., \& Roney, J. R. (2016). The role of physical formidability in human social status allocation. Journal of Personality and Social Psychology, 110(3), 385-406. http://doi.org/10.1037/pspi0000042 
Marsh, A. A., Blair, K. S., Jones, M. M., Soliman, N., \& Blair, R. J. R. (2009a).

Dominance and Submission - The Ventrolateral Prefrontal Cortex and Responses to Status Cues. Journal of Cognitive Neuroscience, 21(4), 713-724.

http://doi.org/10.1162/jocn.2009.21052

Marsh, A. A., Yu, H. H., Schechter, J. C., \& Blair, R. J. R. (2009b). Larger than Life: Humans' Nonverbal Status Cues Alter Perceived Size. Plos One, 4(5), e5707-8. http://doi.org/10.1371/journal.pone.0005707

Mascaro, O., \& Csibra, G. (2012). Representation of stable social dominance relations by human infants. Proceedings of the National Academy of Sciences, 109, 6862-6867. http://doi.org/10.1073/pnas.1113194109

Mascaro, O., \& Csibra, G. (2014). Human Infants' Learning of Social Structures: The Case of Dominance Hierarchy. Psychological Science, 25(1), 250-255. http://doi.org/10.1177/0956797613500509

Mattan, B. D., Kubota, J. T., \& Cloutier, J. (2017). How Social Status Shapes Person Perception and Evaluation: A Social Neuroscience Perspective. Perspectives on Psychological Science: A Journal of the Association for Psychological Science, 12(3), 468-507. http://doi.org/10.1177/1745691616677828

Mondloch, C. J., Gerada, A., Proietti, V., \& Nelson, N. L. (2019). The influence of subtle facial expressions on children's first impressions of trustworthiness and dominance is not adult-like. Journal of Experimental Child Psychology, 180, 19-38. http://doi.org/10.1016/j.jecp.2018.12.002 
Motta-Mena, N. V., \& Scherf, K. S. (2016). Pubertal development shapes perception of complex facial expressions. Developmental Science, 20(4), e12451-10. http://doi.org/10.1111/desc.12451

Murray, G. R. (2014). Evolutionary preferences for physical formidability in leaders. Politics and the Life Sciences, 33(1), 33-53. http://doi.org/10.2990/33_1_33

Murray, G. R., \& Schmitz, J. D. (2011). Caveman Politics: Evolutionary Leadership Preferences and Physical Stature. Social Science Quarterly, n/a-n/a. http://doi.org/10.1111/j.1540-6237.2011.00815.x

Nelson, N. L., \& Russell, J. A. (2015). Children distinguish between positive pride and hubris. Developmental Psychology. http://doi.org/10.1037/dev0000048.supp

Nelson, N. L., Kennedy-Costantini, S., Lee, A. J., \& Dixson, B. J. W. (2019). Children's judgements of facial hair are influenced by biological development and experience. Evolution and Human Behavior, 1-0. http://doi.org/10.1016/j.evolhumbehav.2019.06.002

Nielsen, M., \& Haun, D. (2015). Why developmental psychology is incomplete without comparative and cross-cultural perspectives. Philosophical Transactions of the Royal Society B: Biological Sciences, 371(1686), 20150071-7. http://doi.org/10.1098/rstb.2015.0071

Oosterhof, N. N., \& Todorov, A. (2008). The functional basis of face evaluation. Proceedings of the National Academy of Sciences of the United States of America, 105(32), 11087-11092. http://doi.org/10.1073/pnas.0805664105 
Over, H., \& Carpenter, M. (2014). Children infer affiliative and status relations from watching others imitate. Developmental Science, 18(6), 917-925. http://doi.org/10.1111/desc.12275

Paulus, M., \& Moore, C. (2011). Whom to ask for help? Children's developing understanding of other people's action capabilities. Experimental Brain Research, 211(3-4), 593-600. http://doi.org/10.1007/s00221-011-2676-1

Picci, G., \& Scherf, K. S. (2016). From Caregivers to Peers. Psychological Science, 27(11), 1461-1473. http://doi.org/10.1177/0956797616663142

Pietraszewski, D., \& Shaw, A. (2015). Not by strength alone. Human Nature, 26(1), 4472. http://doi.org/10.1007/s12110-015-9220-0

Pun, A., Birch, S. A. J., \& Baron, A. S. (2016). Infants use relative numerical group size to infer social dominance. Proceedings of the National Academy of Sciences, 113(9), 2376-2381. http://doi.org/10.1073/pnas.1514879113

Pun, A., Birch, S. A. J., \& Baron, A. S. (2017). Foundations of Reasoning About Social Dominance. Child Development Perspectives, 47, 209-6. http://doi.org/10.1111/cdep.12235

Rule, N. O., Adams, R. B., Jr, Ambady, N., \& Freeman, J. B. (2012). Perceptions of dominance following glimpses of faces and bodies. Perception, 41(6), 687-706. http://doi.org/10.1068/p7023

Scherf, K. S., Behrmann, M., \& Dahl, R. E. (2012). Facing changes and changing faces in adolescence: A new model for investigating adolescent-specific interactions between pubertal, brain and behavioral development. Accident Analysis and Prevention, 2(2), 199-219. http://doi.org/10.1016/j.den.2011.07.016 
Sell, A., Bryant, G. A., Cosmides, L., Tooby, J., Sznycer, D., Rueden, von, C., et al. (2010). Adaptations in humans for assessing physical strength from the voice. Proceedings of the Royal Society B: Biological Sciences, 277(1699), 3509-3518. http://doi.org/10.1098/rspb.2010.0769

Sell, A., Cosmides, L., Tooby, J., Sznycer, D., Rueden, von, C., \& Gurven, M. (2009). Human adaptations for the visual assessment of strength and fighting ability from the body and face. Proceedings of the Royal Society B: Biological Sciences, 276(1656), 575-584. http://doi.org/10.1098/rspb.2008.1177

Sell, A., Hone, L. S. E., \& Pound, N. (2012). The Importance of Physical Strength to Human Males. Human Nature, 23(1), 30-44. http://doi.org/10.1007/s12110-0129131-2

Shariff, A. F., \& Tracy, J. L. (2009). Knowing who's boss: Implicit perceptions of status from the nonverbal expression of pride. Emotion, 9(5), 631-639. http://doi.org/10.1037/a0017089

Stolier, R. M., Hehman, E., \& Freeman, J. B. (2018). A Dynamic Structure of Social Trait Space. Trends in Cognitive Sciences, 1-4. http://doi.org/10.1016/j.tics.2017.12.003

Stolier, R. M., Hehman, E., \& Freeman, J. B. (2020). Trait knowledge forms a common structure across social cognition. Nature Publishing Group, 1-15. http://doi.org/10.1038/s41562-019-0800-6

Stulp, G., Buunk, A. P., Verhulst, S., \& Pollet, T. V. (2012). Tall claims? Sense and nonsense about the importance of height of US presidents. The Leadership Quarterly, 1-13. http://doi.org/10.1016/j.leaqua.2012.09.002 
Sutherland, C. A. M., Rhodes, G., Burton, N. S., \& Young, A. W. (2019). Do facial first impressions reflect a shared social reality? British Journal of Psychology, 113, 51318. http://doi.org/10.1111/bjop. 12390

Terrizzi, B. F., Brey, E., Shutts, K., \& Beier, J. S. (2019). Children's developing judgments about the physical manifestations of power. Developmental Psychology, 55(4), 793-808. http://doi.org/10.1037/dev0000657

Terrizzi, B. F., Woodward, A. M., \& Beier, J. S. (2020, February 3). Young children and adults associate social power with indifference to others' needs. PsyArXiv Preprints. http://doi.org/10.31234/osf.io/45uca

Thomas, A. J., Thomsen, L., Lukowski, A. F., Abramyan, M., \& Sarnecka, B. W. (2018). Toddlers prefer those who win but not when they win by force. Nature Publishing Group, 2(9), 662-669. http://doi.org/10.1038/s41562-018-0415-3

Thomsen, L. (2019). The Developmental Origins of Social Hierarchy: How infants and young children mentally represent and respond to power and status. Current Opinion in Psychology, 1-18. http://doi.org/10.1016/j.copsyc.2019.07.044

Thomsen, L., \& Carey, S. (2015). Core Cognition of Social Relations. In Navigating the Social World (pp. 17-22). Oxford University Press. http://doi.org/10.1093/acprof:oso/9780199890712.003.0004

Thomsen, L., Frankenhuis, W. E., Ingold-Smith, M., \& Carey, S. (2011). Big and Mighty: Preverbal Infants Mentally Represent Social Dominance. Science, 331(6016), 477-480. http://doi.org/10.1126/science.1199198

Todorov, A., Olivola, C. Y., Dotsch, R., \& Mende-Siedlecki, P. (2015). Social Attributions from Faces: Determinants, Consequences, Accuracy, and Functional 
Significance. Annual Review of Psychology, 66(1), 519-545.

http://doi.org/10.1146/annurev-psych-113011-143831

Todorov, A., Said, C. P., Engell, A. D., \& Oosterhof, N. N. (2008). Understanding

evaluation of faces on social dimensions. Trends in Cognitive Sciences, 12(12), 455460. http://doi.org/10.1016/j.tics.2008.10.001

Toscano, H., Schubert, T. W., \& Sell, A. N. (2014). Judgments of Dominance from the Face Track Physical Strength. Evolutionary Psychology, 12(1), 147470491401200101. http://doi.org/10.1177/147470491401200101

Toscano, H., Schubert, T. W., Dotsch, R., Falvello, V., \& Todorov, A. (2016). Physical Strength as a Cue to Dominance: A Data-Driven Approach. Personality and Social Psychology Bulletin, 1-14. http://doi.org/10.1177/0146167216666266

Tracy, J. L., \& Robins, R. W. (2008). The nonverbal expression of pride: Evidence for cross-cultural recognition. Journal of Personality and Social Psychology, 94(3), 516530. http://doi.org/10.1037/0022-3514.94.3.516

Tracy, J. L., Cheng, J. T., Robins, R. W., \& Trzesniewski, K. H. (2009). Authentic and Hubristic Pride: The Affective Core of Self-esteem and Narcissism. Self and Identity, 8(2-3), 196-213. http://doi.org/10.1080/15298860802505053

Tracy, J. L., Robins, R. W., \& Lagattuta, K. H. (2005). Can children recognize pride? Emotion, 5(3), 251-257. http://doi.org/10.1037/1528-3542.5.3.251

Van Vugt, M. (2006). Evolutionary Origins of Leadership and Followership. Personality and Social Psychology Review, 10(4), 354-371.

http://doi.org/10.1207/s15327957pspr1004_5 
Van Vugt, M., \& Grabo, A. E. (2015). The Many Faces of Leadership. Current Directions in Psychological Science, 24(6), 484-489.

http://doi.org/10.1177/0963721415601971

Witkower, Z., \& Tracy, J. L. (2019). A Facial-Action Imposter: How Head Tilt Influences Perceptions of Dominance From a Neutral Face. Psychological Science, 30(6), 893-906. http://doi.org/10.1177/0956797619838762

Yu, W., Sun, Z., Zhou, J., Xu, C., \& Shen, M. (2017). Humans Conceptualize Victory and Defeat in Body Size. Scientific Reports, 1-6. http://doi.org/10.1038/srep44136

Zebrowitz, L. A., \& Zhang, Y. (2011). The origins of first impressions in animal and infant face perception. In J. Decety \& J. Cacioppo (Eds.), Handbook of Social Neuroscience. books.google.com http://doi.org/10.1093/oxfordhb/9780195342161.013.0029

Zhao, X., \& Kushnir, T. (2017). Young children consider individual authority and collective agreement when deciding who can change rules. Journal of Experimental Child Psychology, 1-16. http://doi.org/10.1016/j.jecp.2017.04.004 